\title{
The economic impact of broadband: evidence from OECD countries
}

\author{
Pantelis Koutroumpis ${ }^{1}$
}

\begin{abstract}
Information networks have a significant impact on modern economies. This is reflected by their adoption and use across countries along with the increasing quality of the networks. As a result, the impacts on the economy are driven both by the level of adoption and the quality of the connections. Looking at the OECD countries between 2002-2016, I find a consistent effect of broadband adoption on national economic output with diminishing returns to scale. I also find that speed is a moderator of these effects and identify a speed threshold, beyond which further quality increases are deemed unproductive. This speed-threshold increases over time as more applications and skills become available. The measurement of adoption levels and speeds helps formulate a policy tool that guides the development of new communications networks. It also shapes the key priorities in terms of their coverage and quality trade-offs.
\end{abstract}

\footnotetext{
${ }^{1}$ Oxford Martin Technological and Economic Change Programme, Oxford Martin School, University of Oxford, 34 Broad St. OX1 3BD, Oxford, UK.
} 


\section{Introduction}

As an enabler of significant socio-economic activities, broadband networks have been central in the policy debate for more than a decade. In this context the gradual improvements in technology, the use of common protocols and communication standards, the introduction of competition in former monopolies and the significant price reductions in access and equipment have fueled the adoption of digital communications. This progress helped increase the geographical coverage of broadband services, the provision of higher speeds and finally led to the wider adoption of these services turning network access into a legal right for all citizens in the $\mathrm{UK}^{2}$.

Broadband networks are an essential enabling infrastructure in modern knowledge-based economies. Among other general-purpose infrastructures, broadband enables the digitization of adopting sectors including energy, health, education, manufacturing and financial services leading to easier and more efficient information exchange and processing. Given their heterogeneous demand across regions and individuals the policy maker is often faced with the trade-off between: further investments in quality or coverage or the provision of telecommunications services on competitive market terms. These two options may either risk increasing prices for the expanded or faster services or, perhaps, result in providing socially sub-optimal broadband access.

The aim of this paper is to measure the economic impact of broadband ${ }^{3}$ using an econometric method that accounts for the dual nature of the underlying effect: the economic impact as a result of increased broadband use and the effects that higher incomes have on broadband adoption. There are several ways to model this link ranging from experimental designs with treatment variations to growth accounting using macroeconomic data. In the absence of microeconomic data, a standard approach involves the use of different stages in the estimation of the effects. In this paper I use the structural framework proposed by Roller and Waverman (2001) and Koutroumpis (2009). This model measures the direct and reverse effect of broadband use on the local economy combining an aggregate production function with a micro-model of supply, demand and output. This report replicates the model used in Koutroumpis (2009) and updates its findings using an OECD panel of countries for the period 2002 to 2016.

I find that broadband adoption increased GDP by $4.34 \%$ in the OECD area for the period 2002-2016 when fixed broadband connections grew from 3.8 to 31.3 per 100 people. Similarly the broadband speeds in the OECD region increased from a $0.75 \mathrm{Mbps}$ speed in 2002 into $12.85 \mathrm{Mbps}$ in 2016. The GDP change from this speed increase was $1.15 \%$. Combining the effect of the adoption and speed changes contributed $5.49 \%$ to OECD GDP in total over the period or $0.38 \%$ annually on average. While speeds are important for the efficient use of broadband, there are limits - both practical and theoretical - to the actual use of higher speeds on the economy. To model these effects I try to identify the limits beyond which further increases have a zero or negative effect on the economy, due to the unutilized resources devoted to them. I find that this speed thresholds exist and they, in fact increase over time,

\footnotetext{
${ }^{2}$ http://www.telegraph.co.uk/technology/internet/1 1980869/Fast-broadband-to-become-a-legal-right-for-everyone-inBritain-says-David-Cameron.html

${ }^{3}$ Broadband is defined as any type of internet connection (fixed or mobile) capable of providing a minimum of $256 \mathrm{kbps}$ of data throughput. This is the official ITU definition.
} 
from 3Mbps in 2011 to $9.8 \mathrm{Mbps}$ in 2016. These findings combined suggest that the trade-off between coverage and speed exists and aligns with economic intuition.

This paper is organized as follows: in Section 2 I present the relevant literature and in section 3 the econometric model used to measure these findings. In section $4 \mathrm{I}$ briefly describe the data and in Section 5 I discuss the findings and conclude.

\section{Literature}

Today we can isolate several themes related to broadband networks that have emerged since the early days of non dial-up access. First, scholars attempted to understand whether the deployment and use of networks had a measureable impact on the economy or perhaps the opposite effect was in place. The high correlation between broadband adoption and per capita income was indicative of a possible underlying link but the direction of causality was not guaranteed. Researchers were concerned about the residual effect from the use of these infrastructures on the economy that could be negligible or perhaps non-existent. Investments in new infrastructures have a direct effect on output and job creation, but the main interest was to measure the indirect effect of these networks to the broader economy. To address this issue various approaches were introduced with the main aim to disentangle the impact of broadband use from the level of economic development in each country.

In this context some influential papers found remarkably close estimates of this positive link showing that the addition of 10 broadband lines for every 100 people increased GDP by $0.7 \%-1.0 \%$ (Koutroumpis, 2009) and by $0.9 \%-1.5 \%$ (Czernich et al, 2011) respectively. Using a different methodological framework the World Bank reported estimates of $1.21 \%$ for developing countries and $1.38 \%$ for developed (Qiang and Rossotto, 2009). Expanding previous work the European Investment Bank (Gruber et al, 2014) found an annual impact of $1.36 \%$ from broadband adoption.

The effect of broadband networks on job creation has been central to the debate from the very early days of deployment. Researchers have often used availability rather than actual adoption information as a way to address data limitations (for example FCC Form 477 data only showed the number of operators that serve in each postcode). Using this information Gillett et al (2006) showed that communities with broadband availability experienced employment and business growth. This effect was more pronounced for businesses in IT-intensive sectors while the authors did not find any effect on wages. Crandall et al (2007) reported a positive link between broadband adoption and employment showing that for every 1 percentage point increase in broadband penetration in a state, employment increases by $0.2 \%-0.3 \%$ per year.

Using a similar resource to Gillett et al. (2006), Kolko (2012) reported supporting findings using a more robust econometric framework to infer a causal link between broadband availability and economic outcomes. He found that availability caused employment -but not wage - growth mainly in the ICT using industries in the US and also showed that these effects are higher in low-density areas. Using a firm level dataset Forman et al (2012) contradict those findings. They show that advanced Internet is associated with significant wage and employment growth in locations with concentrated IT use, high income, high population and high skills but little evidence of a payoff from Internet investment outside of these locations. 
Other researchers have looked into European samples shedding more light on to the original observations. Aligned with Kolko (2012) findings, Fabritz (2013) analyzed detailed municipal data in Germany and found a positive but rather small effect of ADSL enabled houses and employment growth that is mainly concentrated in regions further apart from large metropolises (further than $32 \mathrm{~km}$ ). Looking into American neighborhoods Whitacre et al. (2014) support the view that broadband adoption instead of availability should be used as a predictor for economic outputs. They also found that income and employment growth are correlated with broadband adoption. Supporting Forman et al. (2012) results and using a firm level dataset as they also did, Canzian et al (2015) use a detailed sample of ADSL2+ coverage and local firms in Italy. They showed that broadband availability was linked with high increases in annual sales and company value but very limited effects on employment growth (Canzian et al, 2015).

Another group of researchers looked into the value that consumers place on their connections as the main focus of study. In this context consumer welfare - the price consumers are willing to pay above the cost of the service provision - is assessed. Measuring this value is not always straightforward. By using the time spent on the Internet Goolsbee and Klenow (2006) traced an increase in consumer welfare ranging from $2 \%$ to $3 \%$ of full income or $\$ 2,500$ to $\$ 3,800$ in the linear case.

Using broadband penetration data Greenstein and McDevitt (2011) estimated a $\$ 4.8$ - \$6.7 billion effect from consumer surplus in the US between 1999-2006. This estimate is remarkably close to Goolsbee and Klenow (2006) given that US population in 2006 was approximately $300 \mathrm{~m}$ and of these $60 \%$ were internet users. Other papers by Rosston et al. (2011) and Ahlfeldt et al (2016) also find significant effects on consumer surplus from internet access that increase with service quality (speed and reliability).

More recently the quality components of broadband delivery have substituted the previous coverage and adoption focus. In response to the launch of national broadband plans with specific speed targets in the US, EU and other countries researchers tried to assess whether the increased investments in quality improvements would bring the foreseen benefits. Broadband speed ${ }^{4}$ has been used as the primary variable of focus in most of these studies. Across these studies researchers seem to agree that basic connections are necessary for the majority of the population and find diminishing returns with speed. Gruber et al (2014) report significant effects from basic speed adoption (higher than 1Mbps) but only marginal effects from higher speeds. Rohman and Bohlin support this view showing that the necessary levels to realize these positive effects appear at 2-4Mbps for OECD countries and 0.5Mbps for Brazil, India and China (BIC) countries. They also indicate that the highest effects appear at the speed range of 4-8 Mbps and that doubling broadband speed contributes $0.3 \%$ to GDP growth ${ }^{5,6}$.

Looking into broadband speeds in the US Rosston et al. (2011) found that the average household is willing to pay about $\$ 20$ per month for more reliable service and $\$ 45-48$ for an increase in speed. Departing from survey data, Ahlfeldt et al (2016) used a rich UK micro-dataset to link broadband speeds as a capitalization effect on property prices. They indicate that a basic connection $(8 \mathrm{Mbps})$ is worth

\footnotetext{
${ }^{4}$ Gruber et al, 2013; Ahlfeldt et al, 2016; Rohman and Bohlin, 2013; Rohman and Bohlin, 2012

${ }^{5}$ The authors here also suggest that diminishing returns exist

${ }^{6}$ A report by the Department of Culture, Media and Sport showed that faster broadband speeds are expected to add $£ 17$ billion to the UK annual GVA by 2024 (average of 0.07 percentage points to real annual gross or net? GVA growth)
} 
$2.8 \%$ of the property price and $3.8 \%$ for a fast connection (24Mbps) supporting the diminishing returns to speed findings. These last two studies find remarkably close estimates for consumer willingness to pay using very different empirical strategies. ${ }^{7}$

\section{The model}

This research replicates the model set out in Koutroumpis (2009). The model is composed of an aggregate production function which links national aggregate economic output $G D P_{i t}$ to a set of production factors in each country $i$ at time $t$. In particular the stock of capital (K), labour (L) and the stock of broadband and fixed telecommunications infrastructure. The stock of broadband infrastructure is used rather than the broadband investment because consumers demand infrastructure and not investment per se. Since the expected growth effects deriving from broadband accrue from the use of the infrastructure I approximate these effects through the level of broadband adoption (BB_Pen). ${ }^{8}$

Aggregate production function

$G D P_{i t}=f\left(K_{i t}, L_{i t}, B B_{-} P e n_{i t}\right)$

Real GDP thus is a function of labour force, capital stock and broadband infrastructure. While the coefficients for labour (L) and capital (K) should be typical for production functions, the coefficient of broadband penetration in equation (1) estimates the one-way causal relationship flowing from the stock of broadband telecommunications infrastructure to aggregate GDP. In order to disentangle the possible effects of broadband telecommunications infrastructure on GDP from the effects of GDP on broadband telecommunications infrastructure, I specify a micro-model for the telecommunications sector in each country consisting of three equations for demand and supply of broadband infrastructure, as well as an infrastructure output function?.

Demand for broadband infrastructure:

$B B_{-} P e n_{i t}=g\left(G D P C_{i t}, B B P r_{i t}, E D U_{i t}, R D_{i t}, U r b_{i t}\right)$

The demand equation (2) links broadband penetration as a function of GDP per capita (GDPC), the price of the broadband service ${ }^{10}$ (BBPr) and other parameters that affect the propensity to adopt broadband technologies, namely the education level in country $i$, the percent of GDP invested in research and development (R\&D) and the level of urbanization (Urb).

\footnotetext{
${ }^{7}$ Turning the monthly effect into a perpetuity with a $5 \%$ interest rate yields $\$ 11,520$ for the change from basic to fast connection in Rosston et al (2011) and \$12,540 in Ahlfeldt et al (2016).

${ }^{8}$ References are given in Table 1 below

${ }^{9}$ Diagnostic tests for multicollinearity are discussed in the Appendix and tables A3 - A5

${ }^{10}$ This variable is collected from ITU (WTID) and is defined as the monthly connection charge for fixed (wired) broadband internet service. Fixed broadband service is considered to be any dedicated connection to the internet with downstream speeds equal to or greater than $256 \mathrm{kbps}$. If several offers are available preference will be given to the $256 \mathrm{kbps}$ (or other minimum connection speed).

Similarly, for broadband speed, fixed broadband speed in Mbps refers to the advertised maximum theoretical download speed and not speeds guaranteed to users associated with a fixed -broadband Internet monthly subscription.
} 
Supply of broadband infrastructure:

$B B_{-} I n v_{i t}=h\left(B B P r_{i t}, H H I_{i t}\right)$

Modeling the supply of fixed telecommunications infrastructure is not always straightforward. Coverage of high-speed networks depends on operators' strategic decisions as well as the socioeconomic and geographic parameters. Equation (3) can thus be seen as a stylized representation of the supply side. Broadband investment per capita $\left(B B_{-} \operatorname{Inv} v_{i t}\right)$ in a country is linked to broadband prices for that period and to competition across technologies. To measure competition across different technologies I estimate the Hirschman Herfindahl Index (HHI) for the relative shares of copper, cable, fibre and other networks in each country. The index ranges from zero to one: in a fully concentrated market where all subscribers use a single platform the index equals 1 . As more platforms are used and subscribers are more evenly distributed across networks the HHI approaches zero.

Broadband infrastructure production function:

$\Delta B B_{-} P e n_{i t}=k\left(B B_{-} I n v_{i t}\right)$

The infrastructure equation (4) links the annual change in broadband penetration with the broadband investment per capita, taken as a proxy of the capital invested in a country during one year. The infrastructure increase is modeled as a function of investment, as this should be the main source of funding of infrastructure growth by broadband firms. Equations (2), (3) and (4) endogenize broadband telecommunications infrastructure because they involve the supply and demand of broadband telecommunications services. The econometric specification of the model is as follows:

Aggregate Production equation:

$\log \left(G D P_{i t}\right)=a_{1} \log \left(K_{i t}\right)+a_{2} \log \left(L_{i t}\right)+a_{3} \log \left(B B_{-} P e n_{i t}\right)+\varepsilon_{1}$

Demand equation:

$$
\begin{aligned}
\log \left(B B_{-} P e n_{i t}\right) & =\beta_{1} \log \left(G D P C_{i t}\right)+\beta_{2} \log \left(B B P r_{i t}\right) \\
& +\beta_{3} \log \left(E D U_{i t}\right)+\beta_{4} \log \left(R D_{i t}\right)+\beta_{5} \log \left(U r b_{i t}\right)+\varepsilon_{2}
\end{aligned}
$$

Supply equation:

$\log \left(B B_{-} I n v_{i t}\right)=\gamma_{1} \log \left(B B P r_{i t}\right)+\gamma_{2} H H I_{i t}+\varepsilon_{3}$

Broadband infrastructure production equation:

$\log \left(\Delta B B_{\text {Pen }_{i t}}\right)=\delta_{1} \log \left(B B_{\text {Inv }_{i t}}\right)+\varepsilon_{4}$

The countries in the sample do not necessarily share the same characteristics with one another in terms of local economic conditions, culture and other location-specific preferences. To account for this variation and to refrain from treating observations from different origins as otherwise identical, I add a full range of country fixed effects in the regressions (Table 2) that help capture these effects. Similarly, there may be temporal variations due to political, social or economic changes within countries that capture seasonal or cyclical trends and business cycles that are reflected in the panel data and would falsely be attributed to the measured phenomenon. I use year fixed effects in all specifications to capture these annual effects. 


\section{Data}

Building on the work of the previous studies, the dataset used in this study consists of annual observations from 35 countries for the fifteen-year period between 2002 and 2016. The countries included in the analysis used are listed in the appendix (Table A1). The data used have been collected by the ITU and the OECD depending on their nature and availability (see Table 1). The HirschmanHerfindahl $\left(\mathrm{HHI}_{\mathrm{it}}\right)$ market and technology concentration index for each country $i$ is calculated ${ }^{11}$ as the sum of the squares of market shares of all technologies in the market at time $t$.

Table 1. Data used in the analysis and sources

\begin{tabular}{lcc}
\hline \multicolumn{1}{c}{ Variable } & Source & Obs \\
\hline GDP (constant 2010 US\$) & OECD & 525 \\
GDP per capita (constant 2010 US\$) & OECD & 510 \\
Gross fixed capital formation (\% of GDP) & OECD & 506 \\
Fixed broadband subscriptions (per 100 people) & OECD & 474 \\
Fixed broadband Internet monthly subscription (US\$) & ITU & 523 \\
Urban population (\% of total) & OECD & 510 \\
Government expenditure on education, total (\% of GDP) & OECD & 387 \\
Research and development expenditure (\% of GDP) & OECD & 386 \\
Fixed (wired)-broadband speed; in Mbit/s & ITU & 305 \\
Annual investment in telecommunication services (US\$) & ITU & 418 \\
Labour force participation rate, total (\% of total population & OECD & 510 \\
ages 15+) (modeled ILO estimate) & ITU & 525 \\
DSL Internet subscriptions & ITU & 525 \\
Fixed-broadband subscriptions & ITU & 525 \\
Cable modem Internet subscriptions & ITU & 525 \\
Fibre-to-the-home/building Internet subscriptions &
\end{tabular}

\section{Results}

The baseline specification Eq. (1)-(4), confirms previous findings and reinforces our understanding of the impact of broadband on the economy (Table 2, Column 1) ${ }^{12}$. Labour and capital have the expected signs, significance and ratios for the set of observations used as they are both positive and highly significant for economic output. Broadband adoption enters the regression with a positive and highly significant coefficient too. On average the OECD sample grew from 3.8 connections per 100 people in 2002 to 31.3 connections per 100 people. The implied GDP impact from this change can be measured using Eq. (5), which links adoption levels and the coefficient for broadband $\alpha_{3}$. Using this formula we

\footnotetext{
${ }^{11}$ Author's calculations from annual data

${ }^{12}$ Column 2 of Table 2 presents results which distinguish between different line speeds. The results for this specification of the model are discussed on page 8 .
} 
can translate broadband adoption changes to increased economic output as it has been used in previous studies (see Roller and Waverman (2001), Koutroumpis (2009) and Gruber and Koutroumpis (2011)):

$$
G D P_{B B P e n}=1-e^{\left(\operatorname{logBBPen}_{2016}-{\left.\log B B P e n_{2002}\right) * a_{3}}\right.}
$$

I find that - during this period - the increase in broadband connections per 100 people contributed to a cumulative GDP increase of $4.34 \%$ for the countries in the sample. A ten-line increase from 20 to 30 lines per 100 people leads to a $0.82 \%$ GDP impact but the effect diminishes with higher adoption rates. An identical ten line increase from 10 to 20 lines yields $1.40 \%$. This estimate is in line with previous findings by Koutroumpis (2009), Qiang and Rossoto (2009) and Czernich et al (2011).

Before moving further in the analysis it is important to explain how broadband affects GDP over time. Imagine two identical economies that only differ in broadband adoption. Apart from the levels, the rate of broadband adoption matters for GDP too. An identical 10-line increase in adoption per 100 people, yields the same GDP effect (level) irrespective of the period over which this is achieved; however a higher rate of increase in broadband leads to a higher annual impact on GDP over a shorter period. This growth rate is sustained until no more subscribers are interested in connecting to the network leading to a saturation point in adoption with no further increases in GDP, other things (especially speeds) being equal. The annual rate of GDP growth is given by Eq. (6) that helps annualize the level effects from increased adoption:

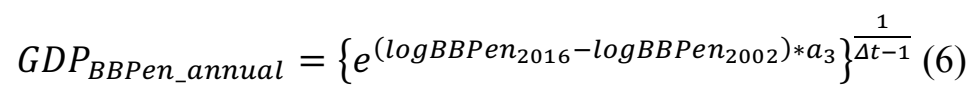

From this formula it is easy to estimate that a 10 line increase (from 20 to 30 lines) over 5 years yields a $0.2 \%$ GDP impact whereas the same change over 10 years yields only $0.09 \%$. The overall effect remains the same but the rate is affected. For the entire period (2002-2016) in the OECD sample the implied GDP effect from broadband is $0.30 \%$ per annum on average. For the UK the effect was $0.37 \%$ per annum on average, with a total impact of 5.28\% (moving from 3 lines per 100 people in 2002 to 38.6 in 2016).

\begin{tabular}{|c|c|c|}
\hline Variables & $\begin{array}{c}\text { 3SLS estimates } \\
\text { (1) }\end{array}$ & $\begin{array}{c}\text { 3SLS estimates } \\
(2) \\
\end{array}$ \\
\hline \multicolumn{3}{|l|}{ Production $\left(G D P_{i t}\right)$} \\
\hline $\begin{array}{l}\text { Fixed stock of capital } \\
\left(\mathrm{K}_{\mathrm{it}}\right)\end{array}$ & $\begin{array}{r}0.152 * * * \\
(0.0272)\end{array}$ & $\begin{array}{r}0.153^{* * * *} \\
(0.0269)\end{array}$ \\
\hline Labour $\left(\mathrm{L}_{\mathrm{it}}\right)$ & $\begin{array}{r}0.848 * * * \\
(0.162)\end{array}$ & $\begin{array}{r}0.823^{* * * *} \\
(0.160)\end{array}$ \\
\hline $\begin{array}{l}\text { Broadband Lines } \\
\left(\text { BB_Pen }{ }_{i t}\right)\end{array}$ & $\begin{array}{r}0.0464 * * \\
(0.0201)\end{array}$ & $\begin{array}{r}0.0482^{* *} \\
(0.0198)\end{array}$ \\
\hline $\begin{array}{l}\text { Broadband Speed } \\
\text { (BB_Speedit) }\end{array}$ & - & $\begin{array}{l}0.0147 * * \\
(0.00613)\end{array}$ \\
\hline
\end{tabular}

Table 2. Econometric results broadband impact, by quality of connections and penetration rate 


\begin{tabular}{|c|c|c|}
\hline \multicolumn{3}{|l|}{ Demand $\left(P E N_{i t}\right)$} \\
\hline GDPC (GDPC $\left.{ }_{i t}\right)$ & $\begin{array}{r}0.286^{* * *} \\
(0.0953)\end{array}$ & $\begin{array}{r}0.287^{* * *} \\
(0.0953)\end{array}$ \\
\hline BB. Price (BB_Prit) & $\begin{array}{r}-0.501 * * * \\
(0.113)\end{array}$ & $\begin{array}{r}-0.502^{* * *} \\
(0.113)\end{array}$ \\
\hline Urbanization & $\begin{array}{r}-0.062 * * * \\
(0.0233)\end{array}$ & $\begin{array}{r}-0.0606 * * * \\
(0.0233)\end{array}$ \\
\hline $\mathrm{R} \& \mathrm{D}$ & $\begin{array}{r}0.521 * * * \\
(0.0874)\end{array}$ & $\begin{array}{r}0.520 * * * \\
(0.0874)\end{array}$ \\
\hline Education level & $\begin{array}{r}0.507 * * * \\
(0.196)\end{array}$ & $\begin{array}{r}0.508^{* * *} \\
(0.196)\end{array}$ \\
\hline \multicolumn{3}{|l|}{ Supply (BB_Invit) } \\
\hline BB Price (BB_Prit) & $\begin{array}{r}0.367 * * * \\
(0.117)\end{array}$ & $\begin{array}{r}0.368 * * * \\
(0.117)\end{array}$ \\
\hline $\mathrm{HHI}\left(\mathrm{HHI}_{\mathrm{it}}\right)$ & $\begin{array}{r}0.583^{* * *} \\
(0.188)\end{array}$ & $\begin{array}{r}0.583^{* * * *} \\
(0.188)\end{array}$ \\
\hline \multicolumn{3}{|l|}{ Output (APenit) } \\
\hline $\begin{array}{l}\text { BB Investment } \\
\text { (BB_Invit) }\end{array}$ & $\begin{array}{l}0.150 * * * \\
(0.00160)\end{array}$ & $\begin{array}{r}0.153^{* * *} \\
(0.0579)\end{array}$ \\
\hline Controls & Yes & Yes \\
\hline Year FE & Yes & Yes \\
\hline Observations & 241 & 241 \\
\hline
\end{tabular}

To maintain this momentum once broadband adoption reaches a saturation point, the intensive margin of the infrastructure has to be exploited through improvements in quality that enable the use of a wider range of services ${ }^{13}$. Since this first estimate (Table 2, column 1) isolates the effect of increased adoption from any other quality improvements that may have taken place during this period I further introduce the speed variable in the regression. For this I add a broadband speed variable in the production function (see Table 2, column 2) to assess the variations in quality of broadband access on GDP. The broadband capital investment in each economy is proxied by adoption in Eq. (1) :

$$
B B_{i t}=B B_{\text {adoption }_{i t}}
$$

As speed is a key predictor of the network quality I rewrite Eq. (7) as:

$$
B B_{i t}=B B_{\text {adoption }_{i t}} X B B_{\text {speed }_{i t}}
$$

Speed is not strictly exogenous as wealthier countries may indeed have higher quality of connections. To proceed with this analysis, I assume that any reverse effect from GDP on speed is largely absorbed by the adoption variable. The production function now becomes:

\footnotetext{
${ }^{13}$ The extensive margin refers to the increase in adoption and the intensive margin to increases in quality (including speed) increases.
} 
$\log \left(G D P_{i t}\right)=a_{1} \log \left(K_{i t}\right)+a_{2} \log \left(L_{i t}\right)+a_{3} \log \left(B B_{P_{\text {en }}}\right)+a_{4} \log \left(B B_{-}\right.$Speed $\left._{i t}\right)+\varepsilon_{1}$

The speed coefficient (measured in Mbps) enters the regression with a positive and significant coefficient as expected. This estimate implies that, possibly, part of the quality improvements at the country level had been captured by country and year controls in the adoption-only results. Substituting adoption with speed in a modified version of Eq. (5) I estimate that increasing speeds from $2 \mathrm{Mbps}$ to $8 \mathrm{Mbps}$ adds $0.9 \%$ on GDP. If this change happens over a period of 10 years it leads to an annual GDP increase of $0.10 \%$ on top of any changes in adoption. A country that achieves this transition in 5 years will increase its annual GDP by $0.22 \%$ leading to a higher annual GDP increase for a shorter period of time. Like adoption, the rate of speed increases matter for GDP as illustrated in this example. Overall the OECD region grew from a $0.75 \mathrm{Mbps}$ speed in 2002 into $12.85 \mathrm{Mbps}$ in 2016. The GDP change from this increase is $1.32 \%$ and the annualized effect $0.09 \%$ (the country level results are shown in Figure 1) . Combining the effect of the adoption and speed changes contributed 5.66\% to OECD GDP in total over the period or $0.39 \%$ annually on average. For the UK, the speed increase contributed $1.71 \%$ to GDP in total and $0.12 \%$ annually. Combining the effect of the adoption and speed changes increased UK GDP by $6.99 \%$ cumulatively and $0.49 \%$ annually on average.

In contrast to the adoption variable that is normalized (minimum of 0 maximum of 1 ) the speed variable does not have similar restrictions. However, the implied linear link between speed and economic growth should not be taken for granted. To test the behavior of this link I modify equation (8) replacing the interaction between adoption and speed with a second order polynomial expression for speed. In this setting the predictor of quality is used to describe the level of readiness across economies rather than the level of adoption. Keeping the polynomial expression within the same setting of Eq. (8) - i.e. multiplied by the level of adoption - would lead to an expression that has no economic meaning. The results of this model are found in the Appendix (Table A2). The negative and significant coefficient in the quadratic term suggests that speed has diminishing returns on GDP. In fact I find that - for the average country in the sample - the highest effects from speed are realized up to a certain speed level. For the time period under consideration, this level is at the maximum of the inverted u-shaped curve with a peak of $9.8 \mathrm{Mbps}{ }^{14}$ The implied effect suggests that there was little - if any - effect for further investments beyond this point at the mean of the distribution of broadband users. This speed threshold varies across countries and over time though. For example, some economies may be able to utilize higher levels of speed during this period and others may be unable to make productive use of even lower levels. This heterogeneity is explained through the "readiness" of the economy to transform the quality of infrastructure into economic outcomes. Taking this observation into consideration reduces the overall GDP effect for the OECD sample to $0.38 \%$ annually or $5.49 \%$ in total. The adoption effect remains at $4.34 \%$ in total while the speed effect drops from $1.32 \%$ to $1.15 \%$, and from $0.09 \%$ to $0.08 \%$ annually on average. For the UK, the overall GDP effect reduces to $0.47 \%$ annually and $6.67 \%$ in total. The adoption effect remains the same but the speed effect reduces from $1.71 \%$ to $1.38 \%$ in total and from $0.12 \%$ to $0.10 \%$ annually on average. The upper speed threshold may be increasing over time as new services appear that help firms and individuals productively use the improved infrastructures.

\footnotetext{
14 The cap is an average across OECD countries, it may differ by country though I am unable to estimate this at country level. This cap is estimated at 3Mbps in 2011 and 6.7Mbps in 2014, i.e. it has been increasing over time.
} 
It is important to note here that broadband speeds can also reach a saturation point. This may happen due to physical limitations of data transfer or because any further increase would make no economic sense (i.e. the data transfer protocols have improved so much that no further investments are necessary in fixed broadband infrastructure). In this case the GDP effects from broadband use can not be explained any further from this model. A country that has reached the saturation point in adoption and speed may experience additional GDP effects but these would not be attributed to the networks anymore. The model used in this analysis and Eq. (6) indicates that any residual GDP returns beyond this point would be attributed to new products and services and not the underlying network that enabled them to appear. This is in line with the impact of other essential but often saturated infrastructures like the transport network, the electricity grid or the water distribution system.

For example, countries with lower average speeds over the period 2002-2016 had a smaller GDP impact from the use of the networks (other things being equal). In Mexico with an average speed of $1.16 \mathrm{Mbps}$ and Turkey with $1.84 \mathrm{Mbps}$ the annual GDP impact from broadband speeds ranged from around $0.06 \%$ to around $0.07 \%$. At the other extreme Korea and Japan, closely followed by Sweden and the UK, have been leading in terms of network quality and speeds (11.58 Mbps and 7.88 Mbps respectively for the period). This has helped them increase their relative gains between $0.12 \%-0.14 \%$ on an annual basis.

Figure 1: The annual GDP impact of broadband by country ${ }^{15}$

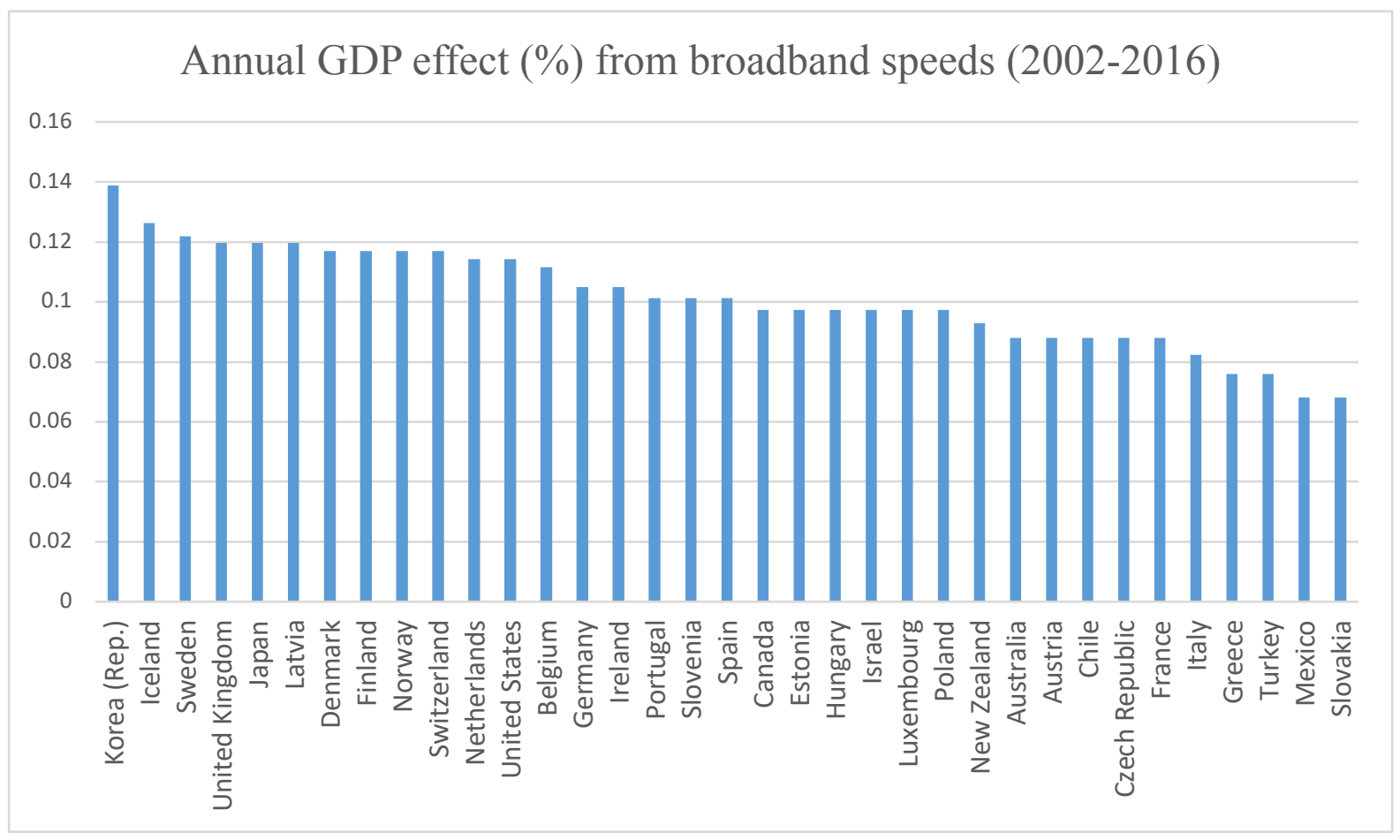

Looking into the rest of the results from Table 2 (column 1 and 2), the demand and supply functions also have the expected results with income as a major contributor to adoption and supply of broadband services. I find that the overall broadband demand proxied by the country level adoption per year is

\footnotetext{
15 These speed effects are not constrained by second order effects. If they were then the theoretical upper bound of speed impacts on GDP would reach a maximum of $0.11 \%$ per annum (if a country started with no broadband in 2002), or an actual upper bound of around $0.1 \%$ per annum. However that would assume that the $9.8 \mathrm{Mbps}$ upper threshold is the same across all OECD countries.
} 
positively linked to income per capita. Broadband prices enter the demand equation with a negative and significant sign confirming the relatively inelastic relationship with broadband adoption.

Urbanization has a negative effect on adoption, which seems counter-intuitive. Investment in broadband networks in urban areas is often more cost-effective and the services offered over the Internet cover urban areas more quickly. Hence it would have been expected that higher urbanization leads to increased broadband adoption. Looking at the variable itself, it is defined as the share of inhabitants in - nationally defined - urban and suburban regions. This lack of a common standard on the definition of regions limits the predictive power of this metric especially in cross-country comparisons ${ }^{16}$.

The other variables in this regression including the average education level in a country and the expenditures in R\&D seem to be positively linked to higher levels of broadband adoption in line with expectations.

The supply equation links the normalized (per capita) annual investment in broadband networks with prices and infrastructure competition. Prices are positively linked to adoption suggesting that, perhaps unsurprisingly, network operators prefer to invest in places where higher revenues are expected. Similarly the more concentrated a market is the higher the propensity to invest, i.e. operators prefer markets with one rather than more competing broadband networks. This link is not linear though; the relationship between market concentration and investment is an inverted U-shaped curve (indicated by a negative quadratic HHI coefficient) with lower investment per capita in a very fragmented or highly monopolized market and higher investments per capita in competitive oligopolies (see Table A2 in the Appendix).

The output equation links broadband investment with the difference in adoption per year. As expected the increase in investment (e.g. in coverage or quality) has a positive and significant footprint on overall adoption.

\section{Discussion}

The findings of this study confirm that broadband adoption affects the economy and that the quality of networks plays a significant role in this process. It is further shown that, for the time period under consideration, the returns from increasing speeds on GDP are positive but diminishing (Table 2 and

\footnotetext{
16 There are various limitations in measuring urbanization according to the World Bank (2017): "Aggregation of urban and rural population may not add up to total population because of different country coverage. There is no consistent and universally accepted standard for distinguishing urban from rural areas, in part because of the wide variety of situations across countries. Most countries use an urban classification related to the size or characteristics of settlements. Some define urban areas based on the presence of certain infrastructure and services. And other countries designate urban areas based on administrative arrangements. Because of national differences in the characteristics that distinguish urban from rural areas, the distinction between urban and rural population is not amenable to a single definition that would be applicable to all countries. Estimates of the world's urban population would change significantly if China, India, and a few other populous nations were to change their definition of urban centres. Because the estimates of city and metropolitan area are based on national definitions of what constitutes a city or metropolitan area, cross-country comparisons should be made with caution". World Bank Data Portal (data.worldbank.org, accessed November 2017)
} 
Table A2). The upper threshold of speed related gains is moving higher as a result of the "readiness" of the economy (individuals or firms) to make productive use of improved infrastructures through the availability of services that demand more bandwidth. This is an important policy implication when future broadband strategies are considered. The rationale of this finding rests with standard economic intuition. Every economy consists of a set of resources and skills that determine its economic capacity: on the extensive margin production can only increase if more labour (of identical skills) or capital is put in place. Still, there are various technologies that help the economy produce more by coordinating its activities, reducing communication costs and improving market conditions by increasing its capital and labour intensive margins (producing more from a more efficient use of the same resources). Through this analysis the maximum GDP effects are found in countries that moved from the lowest to the highest speeds over the period 2002-2016. ${ }^{17}$

As well as the potential for diminishing returns to speed, it is shown that broadband as a network technology has a measureable effect on economic output. Through information exchange, new services and telework it has helped increase GDP by an average of $0.38 \%$ each year for the OECD countries. I show that this effect is related to the quality of infrastructure. On average a country at the highest speeds (capped by the $9.8 \mathrm{Mbps}$ threshold) would gain $0.08 \%$ more on its annual GDP compared to an identical country at the lowest speeds (the lowest quartile in the sample, which is $0-1 \mathrm{Mbps}$ ). This corresponds approximately to a speed increase from $1 \mathrm{Mbps}$ to $10 \mathrm{Mbps}$. Taking into account the diminishing returns to speed a similar change for a country starting from a higher speed in 2002 would have a smaller marginal effect.

Using this information, policy makers can adapt their strategies on two fronts, namely the effects of wider adoption until saturation and the relative merits of higher quality at various levels of adoption. Moreover, these findings provide the ground for comparison across countries and help plan future investments - with variations in public funding - as the costs and benefits accrue from a measureable impact on GDP.

Having analyzed the implications of the findings I discuss the data limitations and caveats related to the methodological design. In this analysis I used national level data - in the absence of more granular information - with the implicit assumption that these can adequately represent the country level conditions. As it has often been observed ${ }^{18}$, there is higher heterogeneity within countries than across them making these observations sensitive to outliers or other types of heavily skewed distributions. Along the same rationale, the use of one observation per year could be improved by more granular observations that help account for seasonal (pricing/advertising campaigns) or cyclical (exchange rates) events commonly found in the evolution of broadband adoption. A number of assumptions need to be made to carry out this analysis. For example, building a year by country panel assumes that there is one type of consumer that matches (or averages) the preferences of all types observed in this country and year. This is a strong assumption and the results should be interpreted with these shortcomings in mind.

\footnotetext{
17 To compute this level for the highest cluster (the top quartile which had speeds $>8 \mathrm{Mbps}$ ) I modified Eq. (1) by adding a variable for speed and speed ${ }^{\wedge}$. The results are show in Table A2, Column2. The maximum speed is calculated by the maximum of the speed curve. Country fixed effects can affect this OECD-level interpretation; also the implied negative impacts of speed on GDP beyond the $9.8 \mathrm{Mbps}$ should be handled as a plateau (see Ahlfeldt, et al 2017).

${ }^{18}$ See Acemoglu and Dell (2010) on productivity between and within countries; also Atkinson, Pikkety and Saez (2011) on inequality; Lakner and Milanovic (2015) on income distributions.
} 
Besides the limitations in data granularity there are other parameters that may affect the results. For example, it is not clear if all broadband plans are available to every user due to the presence - or lack thereof - of various operators across each country. Similarly, there is no information with regards to coverage suggesting that the option to adopt may not be offered to everyone in equal terms with regards to the technologies and networks available. Other national level observations presume a uniform distribution for investments in education or research. These effects may be driven by various factors like the presence of technological hubs or research centers often concentrated around to metropolitan areas or universities.

Beyond the information availability this research incorporates some methods that help measure the impact of broadband on the economy. Evaluation of specific interventions is best measured through quasi-experimental designs where the population is split in a randomly selected treatment and control group. Ideally we would prefer a setting with two identical areas - one with and one without broadband - to test the impact we are after. Since this is not possible I used a closed form framework that tries to mimic broadband market dynamics within an economy. This does not necessarily produce biased results but it is possible to suffer from omitted variables or are other confounding effects (apart from broadband) driving or diminishing the impact of connectivity (i.e. sub-national, cultural, technical, etc.)

In terms of the gaps in the literature there are still several aspects that need to be covered. For instance, there is still a scarcity of studies that tie broadband speeds and firm productivity over a long period of time. Related to this there are no clear links between job creation and redistribution (see Forman et al, 2012) with broadband infrastructure. Apart from the utilization of broadband connections for services hosted within firms there is a substantial part of outsourced storage and computing capacities (IaaS, SaaS, etc) of ICT firms on the cloud. This change may have an impact on the productivity estimates for ICT firms as equipment is not purchased and used as before and increases the dependency towards a faster and more reliable network. This may link other service delivery parameters (like latency) to be factored in future studies.

Last it is important to state that in this modeling framework I have looked into the economic effects of broadband across countries. Other significant effects including life satisfaction and welfare have not been measured although we have evidence that access and use of the networks affects them ${ }^{19}$.

${ }^{19}$ Kavetsos and Koutroumpis (2011); Graham and Nikolova (2013); Penard et al (2013) 


\section{References}

Acemoglu, D., and Dell, M. (2010). Productivity differences between and within countries. American Economic Journal: Macroeconomics, 2(1), 169-88.

Ahlfeldt, G., Koutroumpis, P. and Valletti, T. (2016), Speed 2.0: Evaluating access to universal digital highways. Forthcoming in the Journal of the European Economic Association.

Atkinson, A. B., Piketty, T., and Saez, E. (2011). Top incomes in the long run of history. Journal of economic literature, 49(1), 3-71.

Canzian, G., Poy, S. and Schuller, S. (2015), Broadband diffusion and firm performance in rural areas: quasi-experimental evidence. IZA Discussion Papers 9429, Institute for the Study of Labor (IZA).

Crandall, Lehr and Litan (2007) The effects of broadband deployment on output and employment: a cross-sectional analysis of US data.

Czernich, N., Falck, O., Kretschmer, T. and Woessmann, L. (2011), Broadband infrastructure and economic growth. The Economic Journal, 121: 505-532

Fabritz, N. (2013), The impact of broadband on economic activity in rural areas: evidence from German municipalities. IFO Working Paper No. 166, IFO Institute for Economic Research at the University of Munich.

Forman, C., Goldfarb, A., and Greenstein, S. (2012). The Internet and Local Wages: A Puzzle. American Economic Review, 102(1), 556-575.

Greenstein, S., and McDevitt, R. C. (2011). The broadband bonus: Estimating broadband Internet's economic value. Telecommunications Policy, 35(7), 617-632.

Goolsbee, A., and Klenow, P. J. (2006). Valuing Consumer Products by the Time Spent Using Them: An Application to the Internet. American Economic Review, 96(2), 108-113

Graham C., Nikolova M. (2013) Does access to information technology make people happier? Insights from well-being surveys from around the world. Journal of Socio- Economics, 44, 126-139.

Gruber, H., Hätönen, J. and Koutroumpis, P. (2014). Broadband access in the EU: an assessment of future economic benefits. Telecommunications Policy, 38: 1046-1058

Kavetsos G., Koutroumpis P. (2011) Technological affluence and subjective well-being. Journal of Economic Psychology, 32, 742-753. 
Kolko, J. (2012), Broadband and local growth, Journal of Urban Economics, 71: 100 - 113. doi:10.1016/j.jue.2011.07.004.

Koutroumpis, P. (2009), The economic impact of broadband on growth: a simultaneous approach. Telecommunications Policy, 33 (9): 471-485.

Lakner, C., and Milanovic, B. (2016). Response to Adam Corlett's 'Examining an Elephant: Globalisation and the Lower Middle Class of the Rich World.'. Graduate Center Paper, City University of New York, New York.

Qiang, Christine Zhen-wei, and Carlo M Rossotto. (2009). "Economic Impacts of Broadband." In Information and Communications for Development 2009: Extending Reach and Increasing Impact, 35-50. World Bank

Pénard T., Poussing N., Suire R. (2013) Does the internet make people happier? Journal of Socio-Economics, 46, 105-116.

Röller, L. H., \& Waverman, L. (2001). Telecommunications infrastructure and economic development: A simultaneous approach. American economic review, 909-923.

Rohman, Ibrahim Kholilul, and Erik Bohlin. "Does broadband speed really matter as a driver of economic growth? Investigating OECD countries. "International Journal of Management and Network Economics 2.4 (2012): 336-356.

Rohman, I.K. and Bohlin, E. (2013), Impact of broadband speed on household income: comparing oecd and bic. 24th European Regional Conference of the International Telecommunication Society, Florence, Italy, 20-23 October 2013.

Rosston, Gregory, Scott Savage, and Donald Waldman. 2011. "Household Demand for Broadband Internet Service." Communications of the ACM 54 (2) (February 1): 29. doi:10.1145/1897816.1897830.

SQW. (2013), UK broadband impact study. A Report to the Department for Culture, Media and Sport.

$\mathrm{Vu}, \mathrm{K}$ (2015) ICT as a source of economic growth in the information age: Empirical evidence from the 1996-2005 period -Telecommunications Policy 35 (2011) 357-372

Whitacre, B., Gallardo, R. and Strover, S. (2014), Broadband's contribution to economic growth in rural areas: moving towards a causal relationship. Telecommunications Policy, 38: 1011 - 1023. doi:10.1016/j.telpol.2014.05.005. 


\section{Appendix}

Table A1 lists the countries that have been used in the analysis.

Table A1: Countries included in the dataset

\begin{tabular}{|c|c|c|}
\hline Australia & Hungary & Norway \\
\hline Austria & Iceland & Poland \\
\hline Belgium & Ireland & Portugal \\
\hline Canada & Israel & Slovakia \\
\hline $\begin{array}{l}\text { Chile } \\
\text { Czech }\end{array}$ & Italy & Slovenia \\
\hline Republic & $\begin{array}{l}\text { Japan } \\
\text { Korea }\end{array}$ & Spain \\
\hline Denmark & (Rep.) & Sweden \\
\hline Estonia & Latvia & Switzerland \\
\hline Finland & Luxembourg & $\begin{array}{l}\text { Turkey } \\
\text { United }\end{array}$ \\
\hline France & Mexico & Kingdom \\
\hline Germany & Netherlands & United States \\
\hline Greece & New Zealand & \\
\hline
\end{tabular}

Table A2 provides some additional findings. In Column 1 a quadratic term for $\mathrm{HHI}$ is added to show the inverted U-shape curve that links competition and investments. In Column 2 a quadratic speed term is added to indicate the diminishing returns to speed (and the computation of the maximum level of impact at $9.8 \mathrm{Mbps}$ ).

Table A2: Quadratic speed findings

\begin{tabular}{|c|c|}
\hline Variables & $\begin{array}{c}\text { 3SLS estimates } \\
\text { (3) }\end{array}$ \\
\hline $\begin{array}{l}\text { Production } \\
\left(G D P_{i t}\right)\end{array}$ & \\
\hline $\begin{array}{l}\text { Fixed stock of } \\
\text { capital }\left(K_{i t}\right)\end{array}$ & $\begin{array}{l}0.151 * * * \\
(0.0252)\end{array}$ \\
\hline Labour $\left(\mathrm{L}_{\mathrm{it}}\right)$ & $\begin{array}{c}0.702 * * * \\
(0.160)\end{array}$ \\
\hline $\begin{array}{l}\text { Broadband Lines } \\
\text { (BB_Penit) }\end{array}$ & \\
\hline $\begin{array}{l}\text { Broadband Speed } \\
\text { (BB_Speed) }\end{array}$ & $\begin{array}{c}0.0339 * * * \\
(0.00671) \\
-0.0172 * * *\end{array}$ \\
\hline
\end{tabular}




\begin{tabular}{|c|c|}
\hline $\begin{array}{l}\text { Broadband Speed } \\
\text { squared } \\
\text { (BB Speed) }\end{array}$ & $(0.00251)$ \\
\hline \multicolumn{2}{|l|}{ Demand $\left(P E N_{i t}\right)$} \\
\hline GDPC (GDPCit) & $\begin{array}{c}0.300 * * * \\
(0.0953)\end{array}$ \\
\hline $\begin{array}{l}\text { BB. Price } \\
\text { (BB_Prit) }\end{array}$ & $\begin{array}{c}-0.500 * * * \\
(0.113)\end{array}$ \\
\hline Urbanization & $\begin{array}{c}-0.0610 * * * \\
(0.0233)\end{array}$ \\
\hline $\mathrm{R} \& \mathrm{D}$ & $\begin{array}{c}0.509 * * * \\
(0.0875)\end{array}$ \\
\hline Education level & $\begin{array}{c}0.499 * * \\
(0.196)\end{array}$ \\
\hline \multicolumn{2}{|l|}{ Supply (BB_Invit) } \\
\hline BB Price (BB_Prit) & $\begin{array}{c}0.366^{* * *} \\
(0.117)\end{array}$ \\
\hline $\mathrm{HHI}\left(\mathrm{HHI}_{\mathrm{it}}\right)$ & $\begin{array}{c}0.582 * * * \\
(0.188)\end{array}$ \\
\hline $\mathrm{HHI}^{\wedge} 2\left(\mathrm{HHI}_{\mathrm{it}}\right)$ & \\
\hline \multicolumn{2}{|l|}{ Output (LPen $\left.{ }_{i t}\right)$} \\
\hline $\begin{array}{l}\text { BB Investment } \\
\text { (BB_Invit) }\end{array}$ & $\begin{array}{l}0.154 * * * \\
(0.0579)\end{array}$ \\
\hline \multicolumn{2}{|l|}{ Controls } \\
\hline Country FE & Yes \\
\hline Year FE & Yes \\
\hline Observations & 241 \\
\hline
\end{tabular}

